\title{
Gp96 Peptide Antagonist gp96-II Confers Therapeutic Effects in Murine Intestinal Inflammation
}

\author{
Claudia A. Nold-Petry 1,2*, Marcel F. Nold ${ }^{1,2}$, Ofer Levy ${ }^{3}$, Yossef Kliger ${ }^{3}$, Anat Oren, \\ Itamar Borukhov ${ }^{3}$, Christoph Becker ${ }^{4}$, Stefan Wirtz ${ }^{4}$, Manjeet K. Sandhu ${ }^{1,5}$, \\ Markus Neurath ${ }^{4}$ and Charles A. Dinarello
}

\begin{abstract}
${ }^{1}$ Ritchie Centre, Hudson Institute of Medical Research, Clayton, VIC, Australia, ${ }^{2}$ Department of Paediatrics, Monash University, Melbourne, VIC, Australia, ${ }^{3}$ Compugen Ltd., Holon, Israel, ${ }^{4}$ Medical Clinic 1, Friedrich Alexander University Erlangen-Nuremberg, Erlangen, Germany, ${ }^{5}$ Department of Gastroenterology, Monash Health, Clayton, VIC, Australia,

${ }^{6}$ Department of Medicine, University of Colorado Denver, Aurora, CO, United States
\end{abstract}

\section{OPEN ACCESS}

Edited by:

Guixiu Shi,

Xiamen University, China

Reviewed by:

Ka Man Law,

University of California,

Los Angeles, United States

Bo-Zong Shao,

Second Military Medical

University, China

Dipyaman Ganguly,

Indian Institute of Chemical

Biology (CSIR), India

${ }^{*}$ Correspondence:

Claudia A. Nold-Petry claudia.nold@hudson.org.au

\section{Specialty section: This article was submitted to Inflammation, \\ a section of the journal \\ Frontiers in Immunology}

Received: 14 July 2017 Accepted: 27 October 2017 Published: 11 December 2017

Citation:

Nold-Petry CA, Nold MF, Levy O,

Kliger Y, Oren A, Borukhov I,

Becker C, Wirtz S, Sandhu MK, Neurath M and Dinarello CA (2017)

Gp96 Peptide Antagonist gp96-॥ Confers Therapeutic Effects in Murine Intestinal Inflammation.

Front. Immunol. 8:1531 doi: 10.3389/fimmu.2017.01531
Background: The expression of heat shock protein gp96 is strongly correlated with the degree of tissue inflammation in ulcerative colitis and Crohn's disease, thereby leading us to the hypothesis that inhibition of expression via gp96-II peptide prevents intestinal inflammation.

Methods: We employed daily injections of gp96-II peptide in two murine models of intestinal inflammation, the first resulting from five daily injections of IL-12/IL-18, the second via a single intrarectal application of TNBS (2,4,6-trinitrobenzenesulfonic acid). We also assessed the effectiveness of gp96-II peptide in murine and human primary cell culture.

Results: In the IL-12/IL-18 model, all gp96-II peptide-treated animals survived until day 5 , whereas $80 \%$ of placebo-injected animals died. gp96-II peptide reduced IL-12/ IL-18-induced plasma IFN $\gamma$ by $89 \%, I L-1 \beta$ by $63 \%, I L-6$ by $43 \%$ and tumor necrosis factor (TNF) by $70 \%$ compared to controls. The clinical assessment Disease Activity Index of intestinal inflammation severity was found to be significantly lower in the gp96II-treated animals when compared to vehicle-injected mice. gp96-II peptide treatment in the TNBS model limited weight loss to $5 \%$ on day 7 compared with prednisolone treatment, whereas placebo-treated animals suffered a $20 \%$ weight loss. Histological disease severity was reduced equally by prednisolone (by 40\%) and gp96-II peptide (35\%). Mice treated with either gp96-II peptide or prednisolone exhibited improved endoscopic scores compared with vehicle-treated control mice: vascularity, fibrin, granularity, and translucency scores were reduced by up to $49 \%$ by prednisolone and by up to $30 \%$ by gp96-II peptide. In vitro, gp96-II peptide reduced TLR2-, TLR4- and IL-12/ IL-18-induced cytokine expression in murine splenocytes, with declines in constitutive IL-6 (54\%), lipopolysaccharide-induced TNF (48\%), IL-6 (81\%) and in Staphylococcus epidermidis-induced TNF (67\%) and IL-6 (81\%), as well as IL-12/IL-18-induced IFNy (75\%). gp96-II peptide reduced IL-1 $\beta$, IL-6, TNF and GM-CSF in human peripheral blood mononuclear cells to a similar degree without affecting cell viability, whereas RANTES, IL-25 and MIF were twofold to threefold increased. 
Conclusion: gp96-II peptide protects against murine intestinal inflammation by regulating inflammation in vivo and in vitro, pointing to its promise as a novel treatment for inflammatory bowel disease.

Keywords: Gp96, cytokines and inflammation, biologics, therapeutics, immunemodulatory, anti-inflammatory agent, intestinal inflammation, inflammatory bowel disease

\section{INTRODUCTION}

Inflammatory bowel disease (IBD), which includes Crohn's disease (CD) and ulcerative colitis (UC), is characterized by intense and chronic inflammation of the intestinal tract that damages the epithelium and allows penetration of bacteria across the gut epithelial barrier. Subsequently, T cells infiltrate (1) and release alarmins or damage-associated molecular patterns (DAMPs) such as gp96.

Gp96 is a multifunctional eukaryotic endoplasmic reticulum (ER) heat shock protein (HSP) that is expressed constitutively in virtually all cell types and its synthesis is increased in conditions causing ER stress (2). gp96 plays a chaperone role for most of the toll-like receptors (TLRs) $(3,4)$ that are essential for the innate immune response recognizing microbial products. In addition to its role in innate immunity, gp96 activates the adaptive immune pathways. After tissue damage or viral infection, gp96 is released into the extracellular space and exerts immunestimulatory effects such as $\mathrm{CD}^{+}$cytotoxic $\mathrm{T}$ lymphocyte responses. After receptor-mediated endocytosis by antigenpresenting cells (APC), peptide-loaded gp96 is presented on major histocompatibility complex class I molecules to T cells, which leads to APC activation and increased production of tumor necrosis factor (TNF) and IL-12 (5-7). Extracellular gp96 also induces TLR 4-dependent IL-12 production in dendritic cells (8). Type 1 cytokines, including interleukin (IL)-12 and IL-18, are known to play a key role in human IBD (9-14) and in murine intestinal inflammation (15-17) through their synergistic induction of IFN $\gamma$ synthesis (18).

To elucidate the critical role of gp96 in promoting T-helper 1 (Th1)-mediated intestinal inflammation we applied two different models of murine inflammation. First, we injected mice daily with IL-12/IL-18, which led to murine intestinal inflammation $(15,19$, $20)$. In order to make our preclinical study more generalizable, we chose TNBS (2,4,6-trinitrobenzenesulfonic acid) as our second model. TNBS represents a model of chemical induced intestinal inflammation and is commonly used to mimic a transmural Th-1 cell-dependent colitis, which causes epithelial injury of the colon (17) and has been widely used to study cytokine secretion patterns and effects of immunotherapies (21). We then tested blocking gp96 in both models of disease by injecting a gp96-blocking peptide (gp96-II).

As we have shown previously, gp96-II is a synthetic peptide that binds to and antagonizes gp96-mediated lipopolysaccharide (LPS)-induced cytokine production in freshly isolated human peripheral blood mononuclear cells (PBMCs) and in a murine LPS-induced endotoxin model (22). Others have shown that peptide-based inhibitors to gp96 can block the HSP90-LPS interaction (23) and that the gp96-II peptide inhibits endogenous gp96 in an allogeneic islet transplantation model by improving islet graft function (24).

Our study here shows that gp96-II peptide has actions beyond blockade of TLR pathways, notably by reducing IL-12/IL-18-, IL-1 $\beta$ - and anti-CD3-induced cytokine production in vivo and in vitro. Thus gp96 is a highly prospective target for the development of broad-spectrum therapies against multifactorial diseases such as IBD.

\section{MATERIALS AND METHODS}

\section{Reagents}

RPMI 1640, phosphate-buffered saline (PBS, i.e., vehicle), fetal calf serum (FCS) and penicillin/streptomycin were purchased from Cellgro, Herndon, VA, USA. Pooled human serum was acquired from MP Biomedicals, Solon, OH, USA. LPS (O55:B5), anti-CD3 $\mathrm{mAb}$ and Ficoll Hypaque were from Sigma-Aldrich, St. Louis, MO, USA. Canine gp96 protein (Cat \# G3057-41, US Biological, Swampscott, MA, USA). We purchased the detection kit for lactate dehydrogenase (LDH) from BioVision (Mountain View, CA, USA). Staphylococcus epidermidis (St. epi.) was obtained from the American Type Culture Collection (strain 49134), grown overnight in suspension cultures in LB medium (Difco, Detroit, MI, USA), centrifuged, washed in pyrogen-free vehicle and a small sample was removed for determination of number of organisms by pour plate cultures. The suspension was boiled for $30 \mathrm{~min}$ and then remained at room temperature for $24 \mathrm{~h}$. The boiled suspension was diluted in pyrogen-free vehicle to 10 million organisms per milliliter and frozen in small aliquots at $-70^{\circ} \mathrm{C}$. Recombinant human IL-1 $\beta$, human and murine IL-12 were obtained from Peprotech, Rocky Hill, NJ, USA, and human and murine IL-18 from MBL International, Woburn, MA, USA. The gp96-II peptide is not commercially available and was provided by Compugen, Tel-Aviv, Israel. Peptide designation residues: gp96-II (active) 444-480 LNVSRETLQQHKLLKVIRKKLVRKTLDMIKKIADDKY.

\section{Isolation of Splenocytes, PBMC and Cell Culture}

Spleens of each mouse strain were aseptically removed, macerated and passed through a $70-\mu \mathrm{m}$ cell strainer. Splenocytes were washed with PBS twice, centrifuged and re-suspended in RPMI with $5 \%$ FCS and cultured at $5 \times 10^{6} / \mathrm{ml}$ in a 24 -well flat bottom plate and stimulated as indicated. After $24 \mathrm{~h}$, the supernatant medium was removed for measuring secreted cytokines.

The Colorado Multiple Institutional Review Board approved experiments involving human blood. After informed consent was obtained, PBMCs were isolated from peripheral venous blood of 
healthy volunteers by Ficoll Hypaque density gradient centrifugation. After isolation, cells were counted and examined for viability by trypan blue exclusion. For experiments on PBMC, these cells were used without further treatment. Thereafter, $0.5 \times 10^{6}$ cells were resuspended in $0.3 \mathrm{ml}$ fresh RPMI containing $1 \%$ human serum and primocin and plated into 48-well flat bottom polystyrene plates. Cells were then either stimulated or remained untreated as controls. After 1 day at $37^{\circ} \mathrm{C}$ and $5 \% \mathrm{CO}_{2}$, supernatants were taken and the cells were lysed in lysis buffer $(50 \mathrm{mM}$ Tris, $\mathrm{pH} 7.4,150 \mathrm{mM} \mathrm{NaCl}, 2 \mathrm{mM}$ EDTA, 2 mM EGTA, 10\% glycerol, $1 \%$ Triton X-100, $40 \mathrm{mM} \beta$-glycerophosphate, $50 \mathrm{mM}$ sodium fluoride, $200 \mu \mathrm{M}$ sodium vanadate, $10 \mu \mathrm{g} / \mathrm{ml}$ leupeptin, $10 \mu \mathrm{g} / \mathrm{ml}$ aprotinin, $1 \mu \mathrm{M}$ pepstatin $\mathrm{A}$ and $1 \mathrm{mM}$ phenylmethylsulfonyl fluoride) and frozen at $-80^{\circ} \mathrm{C}$. Before assay, the lysates were clarified by centrifugation at $20,000 \times g$ for $10 \mathrm{~min}$ and the pellet discarded.

\section{Animal Studies}

\section{IL-12/IL-18-Induced Murine Intestinal Inflammation}

Animals-8 to 12-week-old C57BL/6 mice were purchased from The Jackson Laboratory (Bar Harbor, ME, USA), housed five per cage and kept on a 12-h light-dark cycle. The University of Colorado Institutional Animal Care and Use Committee approved all experiments.

After daily intraperitoneal (i.p.) injection of male C57BL/6 (3 months, $20-21 \mathrm{~g}$ ) with $1 \mu \mathrm{g} /$ mouse of IL-12 and IL-18, mice exhibited chronic intestinal inflammation and a type 1 immune response, causing weight loss and increased serum cytokine levels similar to that described in Ref. $(15,20)$. For experiments, animals were injected with IL-12/IL-18 in combination with $60 \mu \mathrm{g} /$ mouse gp96-II peptide (22) and a control group with vehicle. On day 5 , mice were anesthetized by using the OpenDrop exposure to isoflurane and plasma was obtained by orbital bleeding into tubes which contained heparin. Animals were then humanely killed by cervical dislocation and spleens were harvested for splenocyte isolation. A small aliquot of the blood was taken for white blood cell counts.

\section{Clinical Assessment of IL-12/IL-18 Induced Murine Intestinal Inflammation}

Clinical assessment of IL-12/IL-18 induced intestinal inflammation was performed in all animals at day 2 after treatment, before the vehicle animals started to die at day 3 . A combinational index of disease was determined by scoring (research staff blinded to treatment) the change in body weight (\%), stool consistency and occult/gross blood stools (Table 1) (25). The Disease Activity Index (DAI) was then calculated as the average of the three values.

\section{Induction of TNBS (2,4,6-Trinitrobenzenesulfonic Acid) Colitis in Mice}

Eight week old C57BL/6 mice were obtained from the in-house breeding stock at the University of Mainz, Germany. The University of Mainz Animal Care and Use Committee approved all experiments. A total of 60 animals were allocated to 6 groups. The model employs the use of TNBS colitis by administering a total volume of $100 \mu \mathrm{l}$ of $2 \mathrm{mg}$ TNBS intrarectally at day 0 . After
TABLE 1 | Scoring system for Disease Activity Index (DAI).

\begin{tabular}{lcll}
\hline Score & Weight loss (\%) & Stool consistency & $\begin{array}{l}\text { Occult/gross blood } \\
\text { in stools }\end{array}$ \\
\hline 0 & None & Normal stool & No blood \\
1 & $1-5$ & Slightly loose & Slightly bloody \\
2 & $6-10$ & Loose stool & Positive blood \\
3 & $>10$ & Diarrhea & Gross bleeding
\end{tabular}

The degrees of body weight loss, stool consistency and occult/gross blood in stools were quantified as described. The DAl was calculated as the sum of the three scores (25).

Stool consistency: normal stool, stool with an appearance of well-formed pellets; slightly loose stool, loose stool with pasty, semi-formed, soft materials that do not adhere to anal fur; diarrhea, liquid stool that adheres to anal fur. Gross bleeding, an appearance of visible blood adhering to anal fur.

day 1, animals were injected intraperitoneally once daily with either placebo or with corticosteroid (prednisolone: $1 \mathrm{~g} / \mathrm{mouse}$, which we used as a positive control in this setting) or with $60 \mu \mathrm{g} /$ mouse of gp96-II peptide twice daily, over a period of 7 days and weight was monitored daily. On day 7, the animals were humanely killed by cervical dislocation.

\section{Whole Blood Assay}

To investigate the long-term protective effects of gp96-II peptide, we performed ex vivo whole blood assays. Whole blood of animals from the IL-12/IL-18 \pm gp96-II intestinal inflammation model was challenged in vitro with a "second hit" (i.e., stimulation with a TLR2-, TLR4-agonist or IL-1 $\beta$ ) without further in vitro gp96-II peptide treatment. Blood was obtained by orbital bleeding after a 5-day injection series. A small aliquot was taken for white blood cell counts. The remaining whole blood was diluted 1:5 in RPMI and stimulated for $20 \mathrm{~h}$. After this incubation, cultures were lysed with Triton X-100 (final concentration of $0.5 \%$ ) and underwent a freeze-thaw cycle before cytokine determination.

\section{Electrochemiluminescence (ECL) Assays and Enzyme-linked Immunosorbent Assay (ELISA)}

Human IL- $1 \alpha$, IL-1 $\beta$, IL-6, IFN $\gamma$ and TNF as well as murine IL-6, IL- $1 \alpha$, IL-1 $\beta$ and TNF were measured using specific antibody pairs and an Origen Analyzer (Wellstat Diagnostics, Gaithersburg, MD, USA) as described (26). Antibody pairs for all cytokines were obtained from R\&D Systems with the exception of the purchase of IFN $\gamma$ from Fitzgerald Industries International (Concord, MA, USA). Murine IFN $\gamma$ was determined by ELISA (R\&D Systems) according to the manufacturer's instructions. Recombinant cytokines for ECL or ELISA standards were obtained from R\&D Systems or Peprotech (Rocky Hill, NJ, USA).

\section{Cytokine Arrays}

Equal volumes of cell culture supernatants or equal protein concentrations from lysates were incubated with the precoated Human Cytokine Antibody Array membranes (Proteome Profiler Arrays ${ }^{\mathrm{TM}}$, R\&D Systems) according to the manufacturer's instructions. Equal loading of protein was ascertained by densitometry of the positive control spots on the dot blot as well as by measuring total protein; differences in cell death were excluded 
by LDH measurements. Analysis was performed as previously described (26).

\section{Luminex Analysis: In Vitro Study of gp96 Peptide Variants}

Peripheral blood mononuclear cells from three healthy human donors were incubated with nine gp96 peptide variants $(30 \mu \mathrm{g} / \mathrm{ml})$. After addition of $1 \mu \mathrm{g} / \mathrm{ml}$ of LPS for $24 \mathrm{~h}$, or of anti-CD3 $\mathrm{mAb}$ (Sigma, St. Louis, MO, USA) for $48 \mathrm{~h}$, the concentrations of several cytokines were measured in the supernatants using a Luminex analyzer (IS100, Luminex Corporation) and bead-based reagents (Upstate Biotechnology).

\section{Reverse Transcription Quantitative Real- time Polymerase Chain Reaction (RT-PCR)} After $4 \mathrm{~h}$ of LPS stimulation, PBMC cell cultures were spun down and supernatants were analyzed for LDH and human TNF. Total RNA containing miRNAs was extracted from the cell pellet according to the manufacturer's instructions using the mirVana miRNA Isolation kit (Ambion, Austin TX, USA). Primer pair: 18S RNA: Hs99999901_s1 and hTNF Hs99999043_m1 (Applied Biosystems, Foster City, CA, USA).

For mRNA quantification, cDNA was synthesized from isolated RNA using a High Capacity cDNA Reverse Transcription kit (Invitrogen) according to the manufacturer's instructions. Reverse transcription quantitative real-time polymerase chain reaction (RT-qPCR) was performed using an Applied Biosystems 7900HT Fast Real-Time PCR System. Human TNF DNA levels were determined by RT-qPCR with the Taqman ${ }^{\circledR}$ Gene Expression Master Mix by Applied Biosystems (Applied Biosystems, Foster City, CA USA). Fold changes in expression were calculated by the $2^{-\Delta \Delta C q}\left(C_{q}=\right.$ quantification cycle $)$ using the RQ Manager 1.2 and $18 \mathrm{~S}$ FAM as reference gene. The primer/probe sets targeted human TNF. Total DNA content was quantified with a NanoDrop (Thermo Fisher Scientific); each sample was measured in triplicate.

\section{Histology}

The distal colon was taken at necroscopy on day 7, processed, embedded and stained with H\&E as previously described in Ref. (21). An experienced gastroenterologist blinded to the treatment performed scoring. A combined score ranging from 0 to 6 was used to quantify colitis. Inflammatory cell infiltration was scored from 0 to 3 and tissue damage was scored from 0 to 3 . Absence or occasional inflammatory infiltrate in the lamina propria was scored as 0 , increased numbers of inflammatory cells restricted to the lamina propria was scored as 1, inflammatory infiltrates reaching the submucosa was scored as 2 and transmural cell infiltration was scored as 3 . The subscore for tissue damage took into account epithelial lesions with no mucosal damage scored as 0 , focal crypt lesions scored as 1 , surface mucosal erosions or focal ulceration scored as 2 and extensive mucosal damage affecting the submucosa was scored as 3 . The combined inflammatory and histological score resulted in the overall score ranging from 0 (no changes) to 6 (severe inflammatory infiltrate and mucosal damage).

\section{Statistical Analysis}

Data sets (raw data) were first tested for normality and equal variance $(P$ value to reject $=0.05)$ with Sigma Plot 12.5 (Systat software). Thereafter, the appropriate statistical test was applied, which included paired or unpaired Student's $t$-test and/or by the Mann-Whitney rank sum or the Wilcoxon signed rank tests on raw data and one-way analysis of variance (ANOVA) or one-way ANOVA on ranks. All data that underwent statistical analysis are presented either as means of absolute cytokine concentrations, means of normalized cytokine concentrations, or means of percent change \pm SEM.

\section{Ethical Considerations}

This study and protocol were carried out in accordance with the recommendations and approval by the Colorado Multiple Institutional Human Review Board. All subjects gave written informed consent in accordance with the Declaration of Helsinki. The animal studies and protocols were carried out in accordance with the recommendations of the Animal Review Board of the University of Colorado Denver and the Animal Review Board of the University of Mainz.

\section{RESULTS}

\section{gp96-II Peptide Is Protective in Two Murine Models of Intestinal Disease}

Daily injection with IL-12 and IL-18 led to severe acute intestinal inflammation, thereby resulting in symptoms such as bloody diarrhea and fever. IL-12/IL-18-treated mice received either a daily dose of gp96-II peptide or were injected with identical volumes of vehicle. Figure 1A demonstrates the protection afforded by gp96-II peptide against the IL-12/ IL-18-triggered intestinal inflammation. After 5 days, $80 \%$ of the vehicle-injected mice had died, whereas in the gp96-II peptide-treated group, all mice survived. gp96-II peptide also markedly attenuated the IL-12/IL-18-induced weight loss (Figure 1B) and reduced the severity of diarrhea compared with the control group (data not shown). To determine the clinical presentation of IL-12/IL-18-induced intestinal inflammation on all animals, an assessment was performed on day 2, just before vehicle-treated control animals began to perish. The vehicle group presented with diarrhea and bloody stools, which were infrequent or not evident in the gp-96-II-treated group. No gross bleeding was observed in any of the animal groups. The clinical assessment DAI of intestinal inflammation severity was found to be significantly lower in the gp96-II-treated animals when compared to vehicle-injected mice (Figure 1C; Table S1 in Supplementary Material).

Next, we investigated plasma cytokine abundance in the surviving mice on day 5 . As shown in Figure 1D, daily gp96-II peptide injections reduced IL-12/IL-18-induced plasma IFN $\gamma$ by $89 \%$ compared to controls and inhibited plasma cytokine levels of IL- $1 \beta$ by $63 \%$, IL- 6 by $43 \%$ and TNF by $70 \%$ (Figures 1E-G). White blood cell counts showed no significant difference between the groups. 


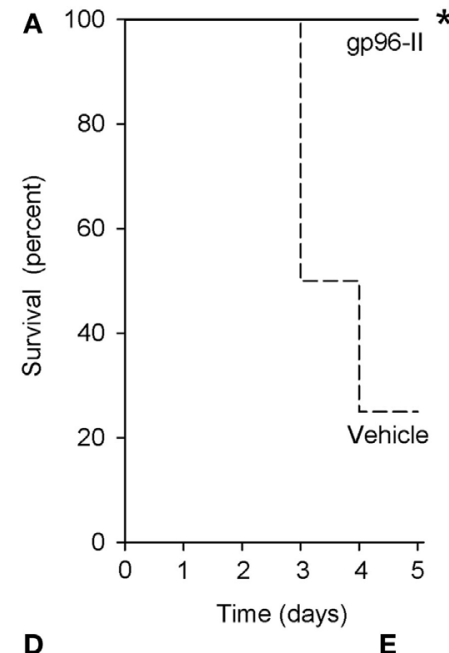

D

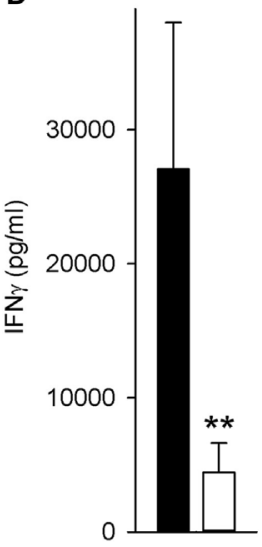

E

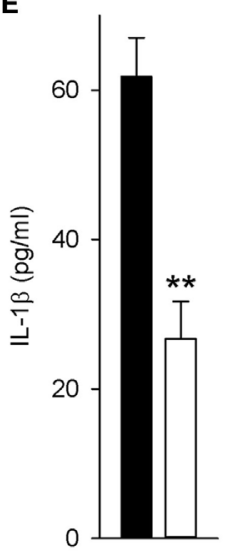

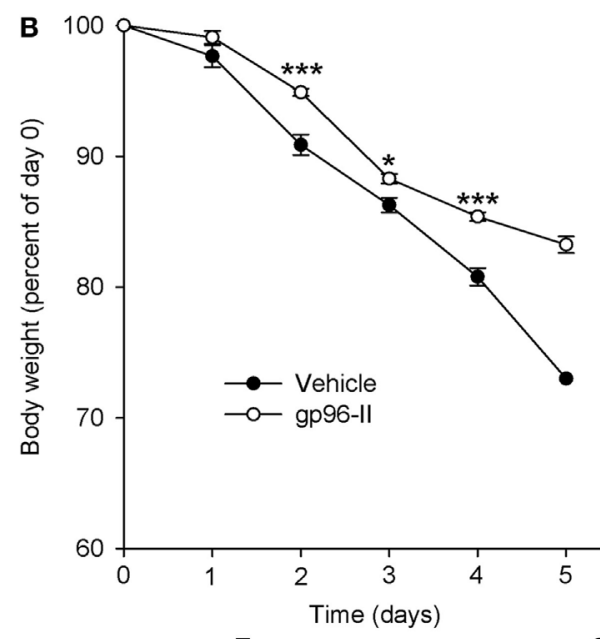

$\mathbf{F}$

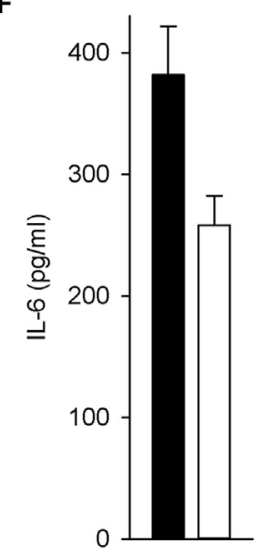

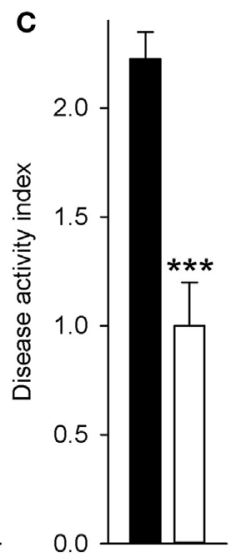

G

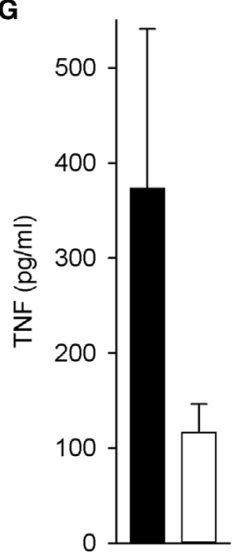

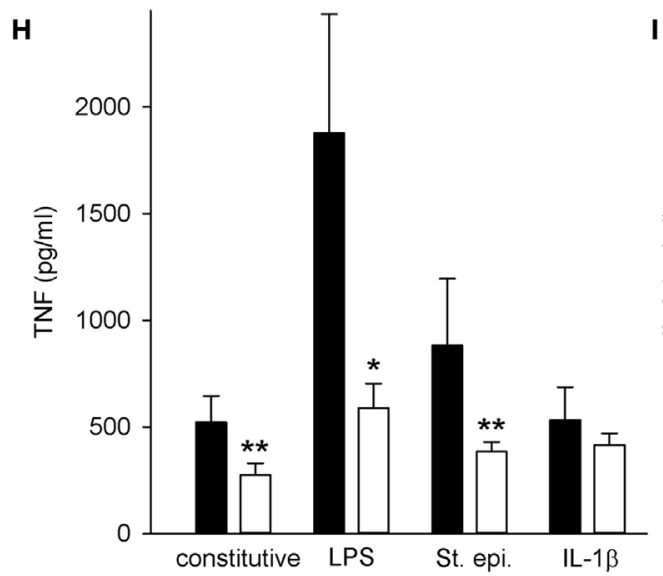

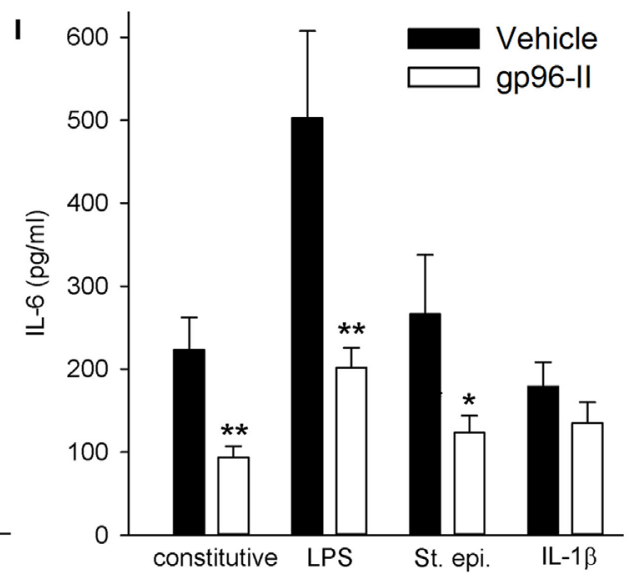

FIGURE 1 | Amelioration of IL-12/IL-18-induced intestinal inflammation by gp96-II peptide in vivo. C57BL/6 mice were injected daily intraperitoneally with either vehicle or gp96-II peptide $(60 \mu \mathrm{g})$ and with IL-12 (1 $\mu \mathrm{g})$ and IL-18 (1 $\mu \mathrm{g})$. (A) Kaplan-Meier analysis of survival of vehicle-treated mice (dashed line) vs. gp96-II peptide-injected mice (solid line). $n=10$ mice per group; ${ }^{*} P<0.05$ for vehicle vs. gp96-II peptide. (B) Means of percent changes in body weight \pm SEM of surviving mice injected with IL-12/IL-18 + vehicle (filled symbols) or IL-12/IL-18 + gp96-II peptide (open symbols). $n=10$ mice per group, identical animals to those in panel (A); ${ }^{*} P<0.05$ and ${ }^{* \star *} P<0.001$ for gp96-Il peptide vs. vehicle. No statistics on last data point as only two survivors in the vehicle group. (C) Disease Activity Index analysis, IL-12/IL-18 + vehicle-injected mice (filled bars) and in animals treated with IL-12/IL-18 + gp96-II peptide (open bars) on day 2 . $n=9-10$ mice per group; ${ }^{\star \star \star} P<0.001$ for gp96-II peptide vs. vehicle. (D-G) Concentrations of plasma IFN $\gamma$, IL-1 $\beta$, IL-6 and tumor necrosis factor (TNF) \pm SEM in IL-12/IL-18 + vehicle injected mice (filled bars) and in animals treated with IL-12/IL-18 + gp96-II peptide (open bars) on day $5 . n=6$ mice per group; ${ }^{\star \star} P<0.01$ for vehicle vs. gp96-II peptide treatment. $(\mathbf{H}, \mathbf{I})$ Comparison of cytokine abundance in ex vivo whole blood assays from mice that had received daily injections with IL-12/IL-18 + vehicle (filled bars) or IL-12/IL-18 + gp96-II peptide (open bars) for 5 days. Whole blood was then challenged in vitro for $24 \mathrm{~h}$ with lipopolysaccharide (1 $\mu \mathrm{g} / \mathrm{ml})$,

Staphylococcus epidermidis $(1: 1,000)$, or $\mathrm{IL}-1 \beta(25 \mathrm{ng} / \mathrm{ml})$. The graphs show means of cytokine concentrations \pm SEM; $n=6$; ${ }^{\star} P<0.05$ and ${ }^{\star \star} P<0.01$ for vehicle vs. gp96-Il peptide, absence of a symbol indicates a non-significant difference. 
Having thus demonstrated that gp96-II peptide is a potent inhibitor of IL-12/IL-18-induced pro-inflammatory cytokines in vivo, we questioned whether residual gp96-II peptide afforded extended protection by performing ex vivo whole blood assays. We studied surviving mice that had either received daily injections with IL-12/IL-18 + vehicle or IL-12/IL-18 + gp96-II peptide. The mice were bled at day 5 and whole blood was challenged immediately in vitro for $24 \mathrm{~h}$ with TLR4-agonist LPS, TLR2-agonist St. epi. or the pro-inflammatory cytokine IL- $1 \beta$, without any addition of gp96-II peptide to the cultures. As shown in Figures 1H,I, residual gp96-II peptide from the in vivo injections inhibited constitutive expression of TNF by $48 \%$ and IL- 6 by $58 \%$. Comparing whole blood from gp96-II and vehicle-treated mice; we found TNF was reduced by $69 \%$ when the second in vitro hit was LPS, $56 \%$ when it was St. epi. and $22 \%$ when it was IL- $1 \beta$. Likewise, IL-6 expression was 60, 53 and 25\% lower in response to all "second hit" conditions.

Our second model inducing colitis caused by intrarectal instillation of TNBS in 50\% ethanol triggered mucosal inflammation mediated by a Th1 response with excessive pro-inflammatory cytokine production (17). The mice were also treated once daily with vehicle as a control, with $1 \mathrm{~g}$ of the corticosteroid prednisolone or twice daily with $60 \mu \mathrm{g}$ of gp96-II peptide. The vehicletreated group exhibited the highest mortality (Figure 2A) and most pronounced weight loss (Figure 2B); both prednisolone and gp96-II peptide completely protected the mice from the deleterious effects of TNBS (Figures 2A,B).

To assess tissue damage, the distal colon of each animal was obtained at necroscopy and sections were H\&E stained and scored, with the assessor blinded to treatment. Prednisolone and gp96-II peptide were equally potent in reducing histological disease severity scores by 40 and $35 \%$, respectively (Figure 2C).

Endoscopy on anesthetized animals on day 3 of the experiment (27) showed that mice treated with gp96-II peptide or with prednisolone had improved endoscopic scores compared with vehicle-treated control mice: vascularity, fibrin, granularity and translucency scores were reduced by up to $49 \%$ by prednisolone and by up to $30 \%$ by gp96-II peptide (Figures 2D-G). As shown in Figure $\mathbf{2 H}$, mice exposed to TNBS displayed changes in intestinal morphology as characterized by edema and infiltration by inflammatory cells in the mucosal and sub-mucosal layers and tissue damage. Daily injections of gp96-II peptide or prednisolone almost completely prevented these morphological changes as shown by significantly ameliorated histological disease severity scores (Figure 1C).

\section{gp96-II Peptide Reduces Cytokines in Freshly Isolated Murine Splenocytes}

gp96-II peptide had an inhibitory effect in freshly isolated murine splenocytes as shown by its action in markedly reducing constitutive IL- 6 by 54\%, LPS-induced TNF and IL- 6 by 48 and $81 \%$ respectively and St. epi.-induced TNF and IL- 6 by 67 and $81 \%$ respectively (Figures 3A,B). gp96-II peptide inhibited IL-12 + IL-18-induced IFN $\gamma$ secretion by $75 \%$ at a concentration of $60 \mu \mathrm{g} / \mathrm{ml}$ (Figure 3C).

\section{Inhibition of LPS-Induced TNF mRNA by gp96-II in PBMC Does Not Affect Cell Viability}

Treatment of PBMC with $30 \mu \mathrm{g} / \mathrm{ml}$ gp96-II peptide decreased TNF mRNA expression at $4 \mathrm{~h}$, under steady-state conditions by $80 \%$ and after LPS stimulation by $52 \%$ (Figure 4 A). Accordingly, protein abundance of LPS-induced TNF was also decreased (Figure 4B) by up to $53 \%$. Ruling out the possibility that the anti-inflammatory effects of gp96-II peptide were attributable to cell death, we found no increase in $\mathrm{LDH}$ in the culture supernatants of PBMC treated with 15, 30, 60 and $120 \mu \mathrm{g} / \mathrm{ml}$ of gp96-II peptide for $4 \mathrm{~h}$ compared to vehicle; in fact, gp96-II peptide negated the small increase in LDH induced by LPS in PBMC (not shown). We also performed flow cytometry to investigate the effect of gp96-II peptide on specific subpopulations of PBMC. In cells treated with vehicle, LPS alone or LPS + gp96-II peptide $(30 \mu \mathrm{g} / \mathrm{ml})$ for $20 \mathrm{~h}$, we found no differences in overall viability, in the percentage of lymphocytes and macrophages among live cells or in the percentage of $\mathrm{CD}^{+}{ }^{+} \mathrm{T}$-cells and $\mathrm{CD} 19^{+} \mathrm{B}$-cells among lymphocytes (not shown).

\section{Anti-inflammatory Activity Screening of Nine gp96 Peptide Variants}

To determine the best anti-inflammatory gp96 peptide variant, we tested nine different gp96 peptide variants, termed gp96-I to -IX, in PBMC at a concentration of $30 \mu \mathrm{M}$. As shown in Figures S1A,B in Supplementary Material, peptide gp96-II (CGEN-25007) reduced LPS-induced IL- 6 by $91 \%$, IL- 8 by $93 \%$, MIP- $1 \alpha$ by $73 \%$, IL- $1 \beta$ by $93 \%$ and TNF by $60 \%$ compared to the other peptides and even outperformed the inhibitory effects of dexamethasone. Reduction of anti-CD3-induced cytokine production by gp96-II peptide was comparable for IL-1 $\beta$, IL-12p40, IL-12p70 and TNF, whereas IL-1 $\alpha$, GM-CSF and IL-2 were not affected (Figures S1C,D in Supplementary Material). These data confirm that gp96-II peptide (CGEN-25007) is the peptide with most potent anti-inflammatory activity in LPS- as well as anti-CD3-stimulated PBMC.

\section{gp96-II Peptide Abrogates Production of Pro-inflammatory Cytokines in Human PBMC}

To investigate the clinical relevance of gp96-II peptide on inhibition of TLR2/4- or IL-1b-triggered inflammatory responses in primary human cells, we isolated fresh PBMCs and stimulated them with gp96-II peptide, either alone or in combination with LPS, or with heat-killed St. epi. or IL-1 $\beta$. We found that gp96-II peptide effectively blocked the production of pro-inflammatory cytokines in PBMC. For example, 60 and $120 \mu \mathrm{g} / \mathrm{ml}$ gp96-II peptide decreased the concentrations of LPS-induced IL-1 $\alpha$ (by 50 and $98 \%$, respectively), IL-1 $\beta$ (by 72 and $99 \%$, respectively), IL-6 (by 70 and $94 \%$, respectively) and TNF (by 70 and $94 \%$, respectively) compared with LPS alone (Figures 5A-D). Inhibition of the induction of pro-inflammatory cytokines by St. epi. was similar.

We also tested IL- $1 \beta$ as a pro-inflammatory stimulus and observed that $30 \mu \mathrm{g} / \mathrm{ml}$ of gp96-II peptide was sufficient to 

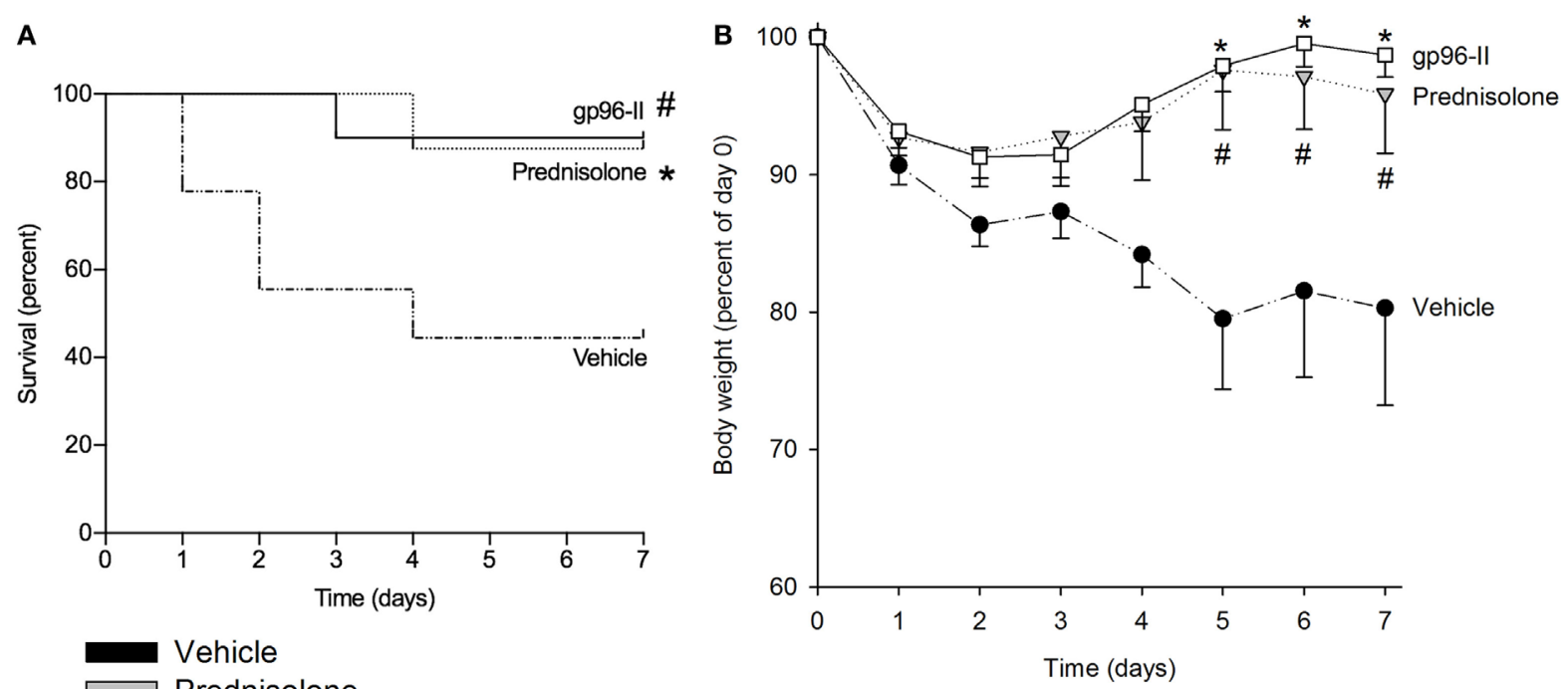

Prednisolone gp96-II
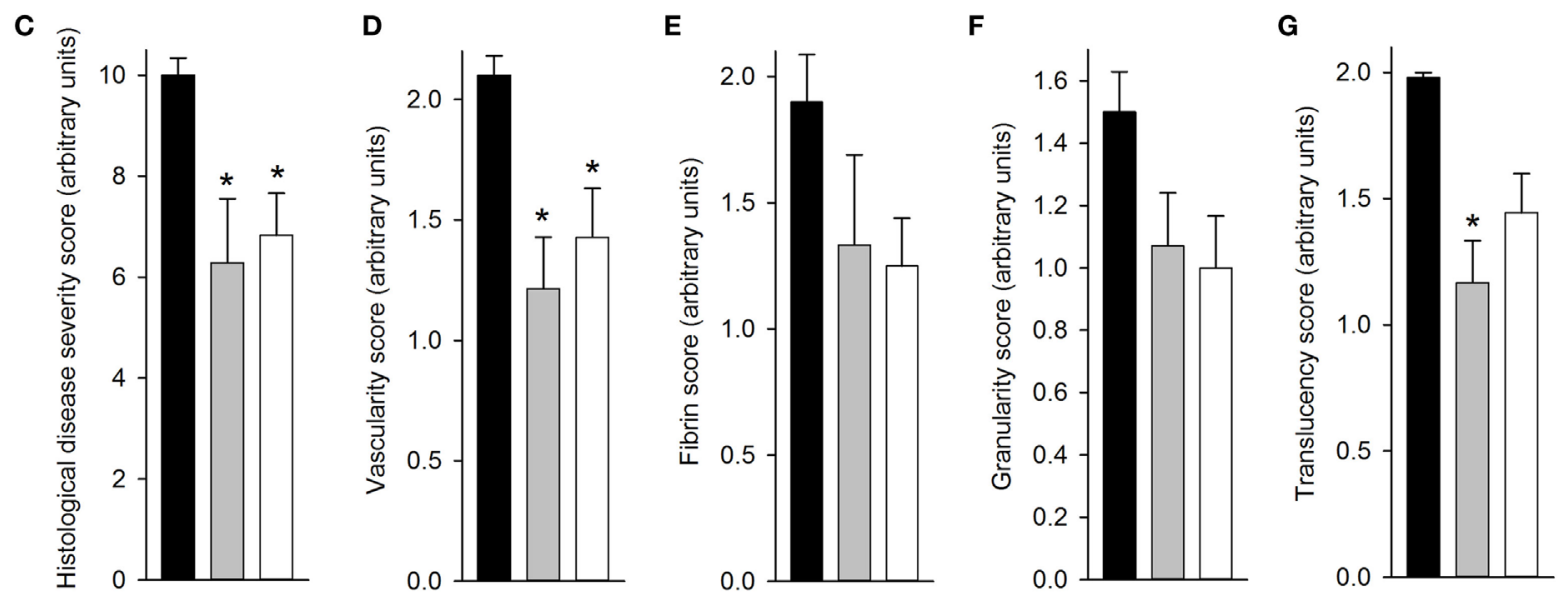

H

Vehicle

Prednisolone

gp96-II
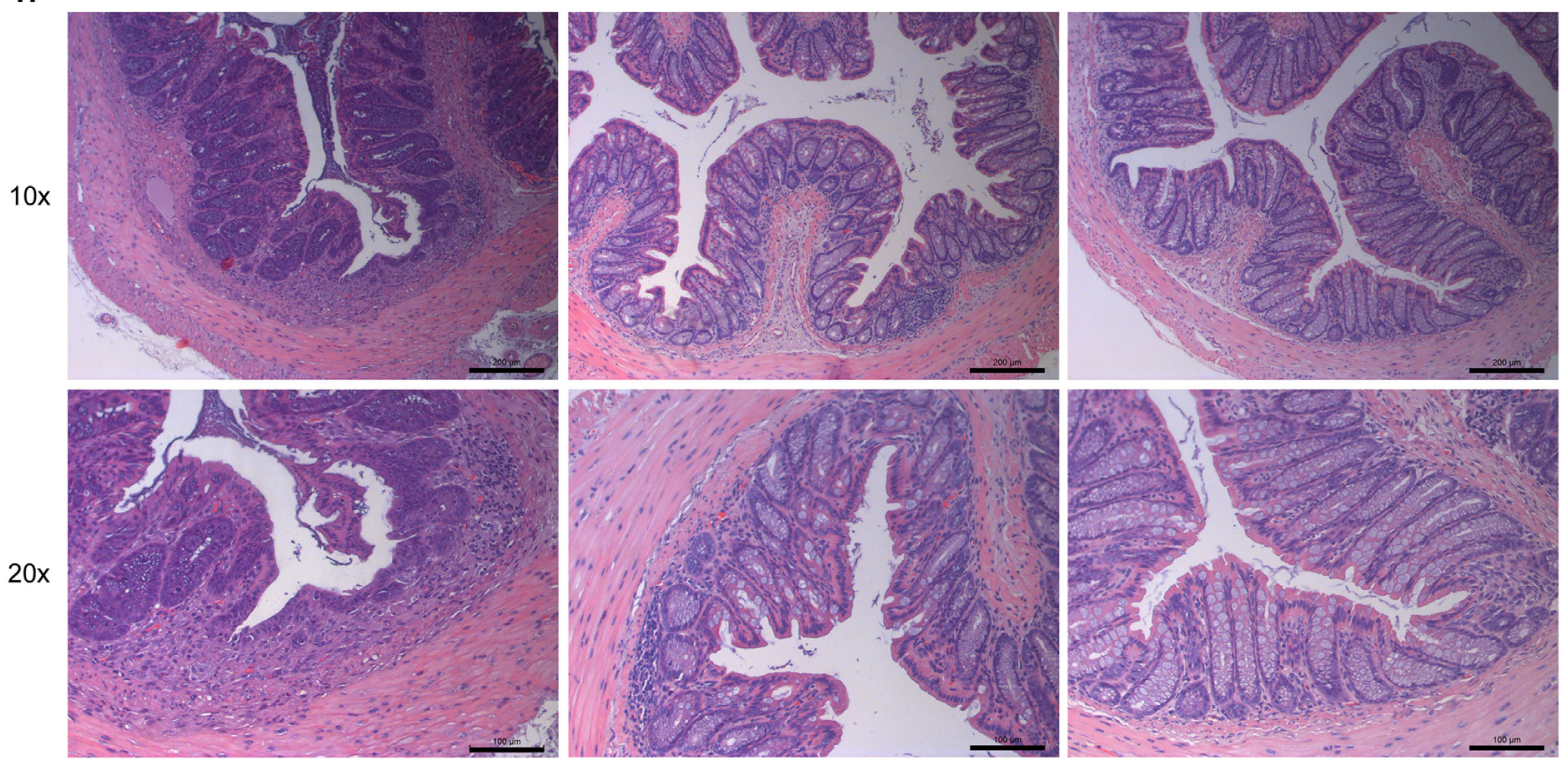


\section{FIGURE 2 | Continued}

Amelioration of TNBS-induced colitis by gp96-II peptide. Colitis was induced by intrarectal application of TNBS on day 0. Male C57BL/6 mice either received twice daily intraperitoneal injections of vehicle or gp96-II peptide $(60 \mu \mathrm{g})$, or were administered prednisolone $(1 \mathrm{~g})$ once daily for 7 days. (A) Kaplan-Meier analysis of survival of vehicle-treated mice (dashed line) vs. gp96-II peptide-injected mice (solid line) or vs. prednisolone injected mice (dotted line). $n=10$ mice per group; ${ }^{\sharp} P<0.05$ for vehicle vs. gp96-II peptide, ${ }^{*} P<0.05$ for vehicle vs. prednisolone. (B) Bodyweight in percent of day $0 \pm$ SEM is shown for the gp96-II peptide (open squares) $(n=10)$, prednisolone (gray triangles) $(n=8)$ and vehicle (solid circles) groups $(n=9) ;{ }^{*} P<0.05$ for gp96-II peptide vs. vehicle; ${ }^{*} P<0.05$ for prednisolone versus vehicle. (C) Postmortem histological disease severity scores of the colons (arbitrary units; see Materials and Methods) on day $7 \pm$ SEM. (D-G) Endoscopy was performed on anesthetized mice on day 3 of the experiment and vascularity, fibrin, granularity and translucency scores (arbitrary units \pm SEM) were obtained. $n=7$ in the vehicle (filled bars) and prednisolone (gray bars) groups, $n=9$ in the gp96-II peptide group (open bars); ${ }^{*}<<0.05$ for gp96-II peptide or prednisolone vs. vehicle, absence of a symbol indicates a non-significant difference. $\mathbf{( H )}$ Intestinal sections were H\&E stained and analyzed on day $7, n=7-9$ per group. One representative image per treatment group depicting the colon at a low (10x) and high (20x) magnification. Scale bars: $200 \mu \mathrm{m}$ for $10 \times$ magnification and $100 \mu \mathrm{m}$ for 20x magnification.

inhibit production of IL-1 $\alpha$ (Figure 5A), an unexpected result as $30 \mu \mathrm{g} / \mathrm{ml}$ did not reduce TLR-induced cytokines (Figure 5D). However, IL-1 $\beta$-induced IL- 6 and TNF remained unaffected by 30 and $60 \mu \mathrm{g} / \mathrm{ml}$ of gp96-II peptide. In addition, we investigated the effect of gp96-II peptide on IL-12/IL-18-induced IFN $\gamma$ in human PBMC (Figure 5E). gp96-II peptide inhibited IL-12/ IL-18-induced IFN $\gamma$ secretion in human PBMC at a concentration of $30 \mu \mathrm{g} / \mathrm{ml}$ (by 20\%) and at $60 \mu \mathrm{g} / \mathrm{ml}$ (by 61\%) after $24 \mathrm{~h}$ and by $82 \%$ after $48 \mathrm{~h}$ (Figure 5E). Compared to TLR ligands, induction of IL- $1 \beta$, IL- 6 , IL- $1 \alpha$ and TNF was moderate; however, the magnitude of the reduction in IL- $1 \alpha$ by gp96-II peptide at $60 \mu \mathrm{g} / \mathrm{ml}$ was $50 \%$ (not shown). To rule out unspecific effects of the gp96-II peptide, we showed that mutated nonsense peptides had no effect on any of the parameters we assessed (not shown).

Having observed that gp96-II peptide was highly effective in reducing TNF, IL-1 $\beta$, IL- 6 and IL- $1 \alpha$, we further investigated the effect of gp96-II peptide in LPS-stimulated PBMC using an array of 40 human mediators of inflammation. Figure 6A shows the increase in cytokine abundance and Figure 6B shows the decrease in cytokine abundance. In addition to confirming the results described above, the array revealed decreases in the abundance of GM-CSF and IL-1Ra, as well as increases in RANTES (threefold), IL-25 and MIF (twofold to threefold), whereas IL-10, IL-4 and IL- 5 were measured but were undetectable in all conditions.

\section{DISCUSSION}

Inflammatory bowel disease, which encompasses UC and CD, is a chronic disorder characterized by severe intestinal inflammation. Our aim was to advance the prospects for anti-inflammatory agents by focusing on the role of the DAMP molecule gp96 in IBD. The data we present here provide new mechanistic insights into the role of gp96 in IBD. Our major findings are that the synthetic molecule gp96-II peptide binds to and thereby blocks the pro-inflammatory activities of HSP gp96 via inhibition of TLR signaling and amelioration of intestinal inflammation. Furthermore, our study shows that the inhibitory functions of gp96-II peptide protect against cytokine-induced inflammation in PBMC from healthy human donors and primary murine cells. Our detailed analysis of gp96-II peptide provides new insights into the broad mechanistic functions of gp96 and highlights the value of gp96-II peptide as a starting point in the design of small molecule inhibitors for inflammatory diseases of the intestine.
Before performing any in vivo testing in murine models of intestinal disease, we first screened nine different gp96-IIs in vitro to assess their inhibitory properties. We found that the peptide gp96-II provided the most potent and versatile inhibition. Thus, we demonstrated that inflammation induced by $\mathrm{T}$ cell activation via CD3 ligation in PBMC is reduced with gp96-II peptide to a similar degree compared with its inhibitory effects on LPS-induced inflammation. gp96-II peptide thus acts as a multifunctional immune blocking agent, adding to earlier evidence that gp96-II peptide inhibits TLR2- and TLR4-induced pro-inflammatory (27) response in PBMC and murine splenocytes (22).

Our efforts in this study were directed at a more detailed analysis of the inhibitory effects of gp96-II peptide on pro-inflammatory cytokines and the associated immunobiology. The choice of IL-12/ IL-18 for the creation of an inflammatory condition to model IBD was based on several studies. Among the pro-inflammatory cytokines, the IL-1 family member IL-18 plays an important role in a range of immune-mediated pathologies. For example, in 1999, three groups independently reported the pathological role of IL-18 in IBD patients (10-12). Subsequent studies confirmed that IL-18 has a role in the pathogenesis of human IBD as well as in murine intestinal inflammation $(15,16,28-30)$. The high level of IL-18 that is generated in the inflamed gut causes further damage of the intestinal epithelium, thereby promoting penetration of gut bacteria across the compromised mucosa and later infiltration of T cells (1). Subsequently, alarmins and DAMP factors such as gp96 are released.

Extracellular gp96 then activates TLR2 and TLR4 and increases synthesis of pro-inflammatory cytokines (8), including vigorous IFN $\gamma$ production by $\mathrm{T}$ cells, profound inflammatory responses and IBD pathology (9). In addition, gp96 is overexpressed in ileal epithelial cells in biopsies from patients with CD and promotes mucosal invasion of bacteria such as Escherichia coli (31). Tissues from CD patients are known to have elevated IL-12 transcripts and their lamina propria mononuclear cells produce higher levels of IL-12 compared to healthy subjects (13). Moreover, gp96 activates dendritic cells via the TLR2 and TLR4 pathways (8), and dendritic cells and macrophages produce more IL-12 in patients with CD, leading to a prototypical activation of APC and a shift toward Th1 differentiation (32). These findings support a strong pathological association of gp96, IL-12 and IL-18 in inflammatory diseases of the gut and highlights the importance of gp96 as a key-signaling player in intestinal type 1 immune responses. 


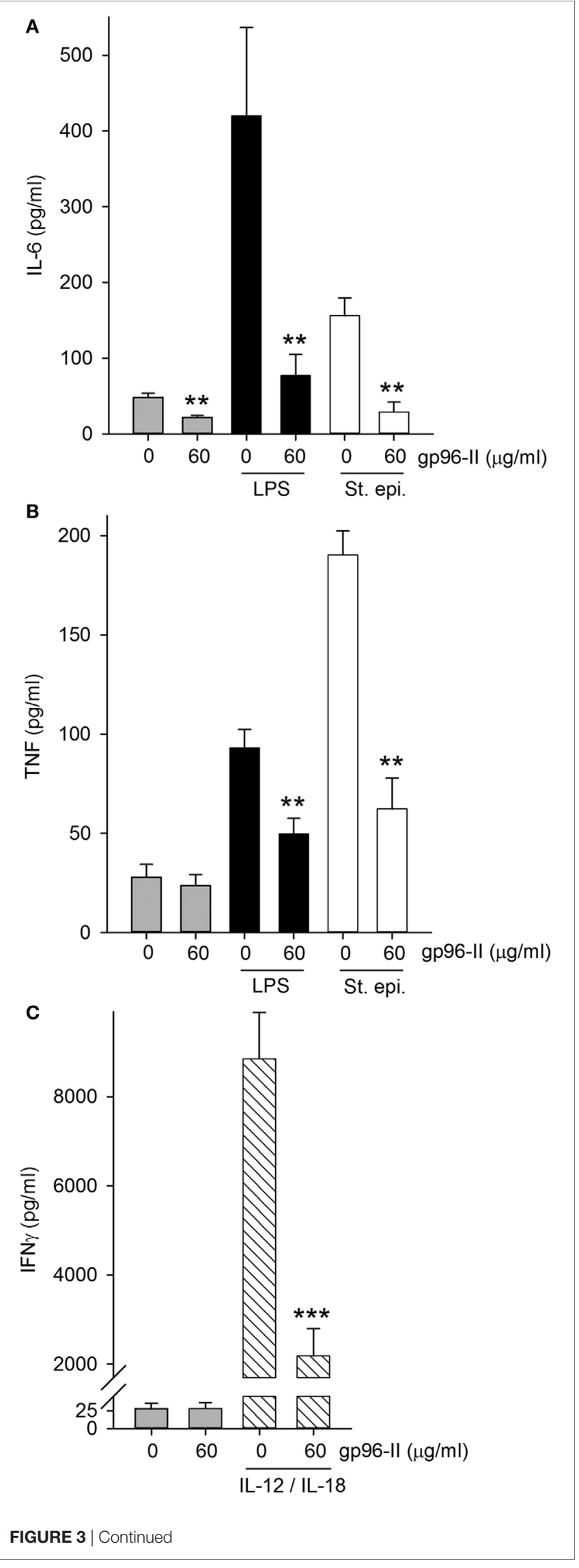

\section{FIGURE 3 | Continued}

Effect of gp96-II peptide on TLR- or IL-12/IL-18-induced cytokine production in murine splenocytes. $(\mathbf{A}, \mathbf{B})$ Cells were incubated for $24 \mathrm{~h}$ with vehicle, lipopolysaccharide (LPS) (100 ng/ml), or Staphylococcus epidermidis (St. epi.) $(1: 4,000)$ in the presence or absence of gp96-II peptide $(60 \mu \mathrm{g} / \mathrm{mll})$. The graphs display means of absolute cytokine abundance \pm SEM. (C) IFN $\gamma$ protein abundance in cells stimulated for $24 \mathrm{~h}$ with either vehicle or $\mathrm{IL}-12$ $(20 \mathrm{ng} / \mathrm{ml})+\mathrm{LL}-18(50 \mathrm{ng} / \mathrm{ml})$ in the presence or absence of $60 \mu \mathrm{g} / \mathrm{ml}$ of gp96-II peptide. $n=6$; ${ }^{* *} P<0.01$ and ${ }^{\star * \star} P<0.001$ for LPS, St. epi. or IL-12/ IL-18 alone vs. stimulus + gp96-II peptide.
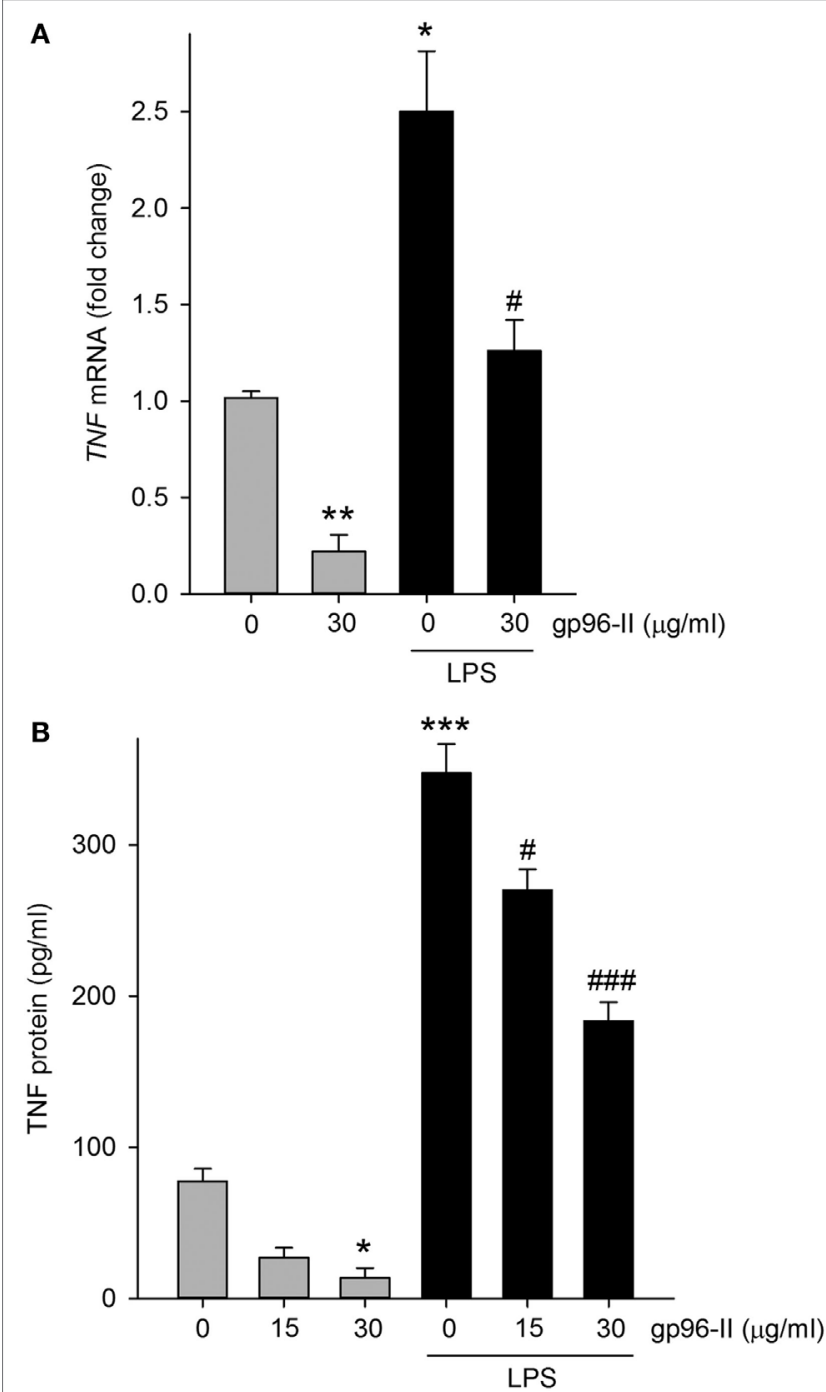

FIGURE 4 | Tumor necrosis factor (TNF) mRNA and protein in lipopolysaccharide (LPS)-stimulated peripheral blood mononuclear cells with and without gp96-II peptide. Cells were incubated with or without LPS in combination with gp96-II peptide $(30 \mu \mathrm{g} / \mathrm{ml})$ for $4 \mathrm{~h}$. (A) Fold change in TNF mRNA \pm SEM; (B) TNF protein abundance \pm SEM. $n=5$; ${ }^{*} P<0.05 ;{ }^{* *} P<0.01$; and ${ }^{\star \star *} P<0.001$ for control vs. stimulation with LPS or gp96-II peptide alone; ${ }^{P} P<0.05$ and ${ }^{\# \# P} P<0.001$ for LPS plus gp96-II peptide vs. LPS alone.

Another important function exerted by IL-12 and IL-18 in synergy is a potent induction of IFN $\gamma$ in vivo and in vitro (15, $19,20,33,34)$, especially in IBD. One particular focus of our 

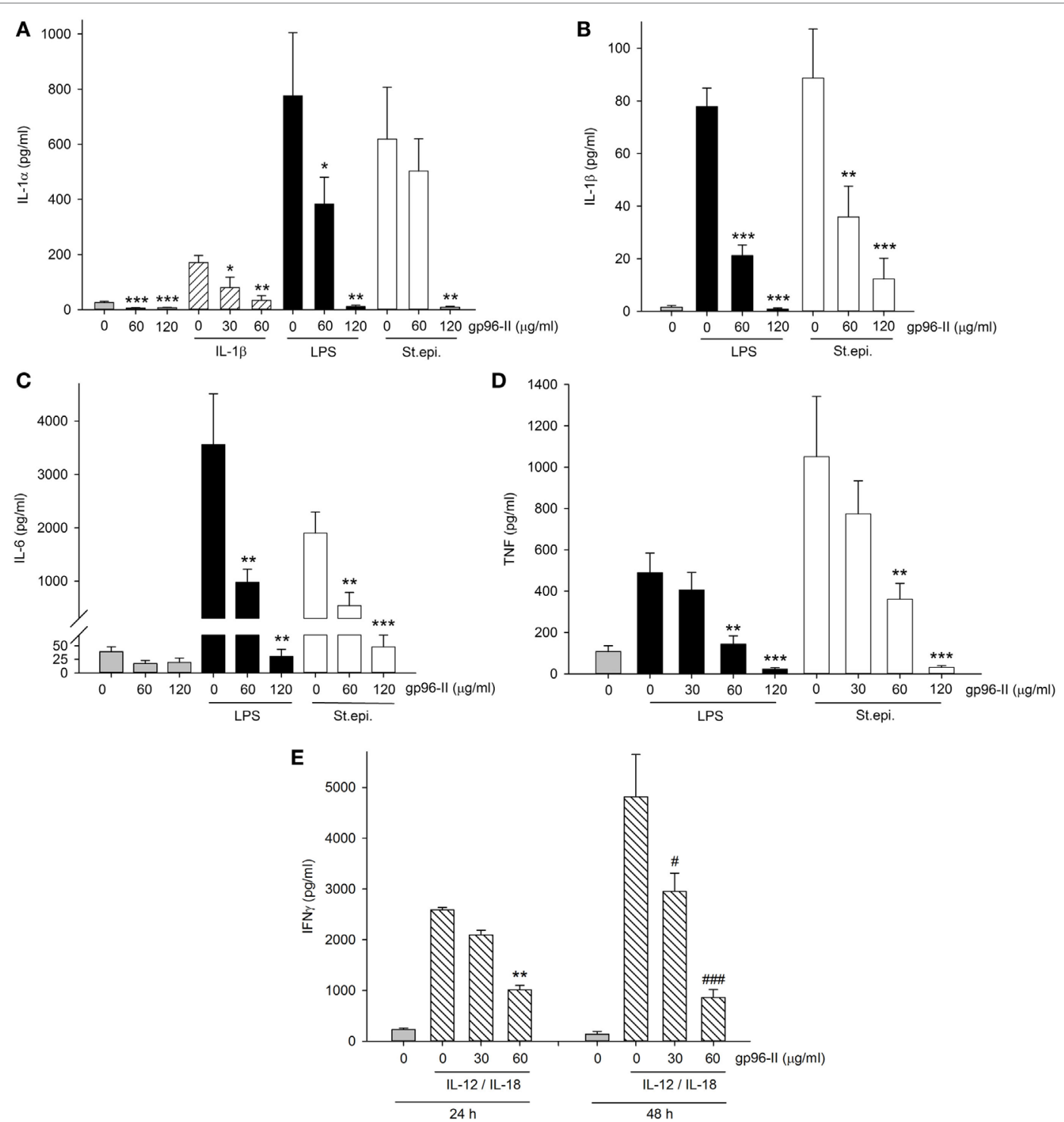

FIGURE 5 | Effect of gp96-II peptide on TLR- and cytokine-induced cytokine production in human peripheral blood mononuclear cells (PBMC). (A-D) Cells were

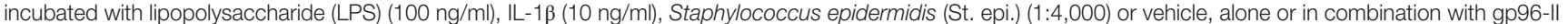
peptide for $24 \mathrm{~h}$. The concentrations of gp96-II peptide in micrograms per milliliter are indicated. Lysates (A) or supernatants (B-D) were analyzed for cytokine abundance. The panels depict means of absolute concentrations of cytokines \pm SEM, $n=4$; ${ }^{*} P<0.05$; ${ }^{* \star} P<0.01$; ${ }^{* \star \star} P<0.001$ for IL-1 $\beta-$, LPS-, or St. epi.stimulated cells + gp96-II peptide vs. stimulated cells alone. (E) PBMC from four donors were incubated for the indicated periods of time in the presence or absence of IL-12 $(20 \mathrm{ng} / \mathrm{ml})+\mathrm{IL}-18(25 \mathrm{ng} / \mathrm{ml})$ with or without gp96-II peptide at the indicated concentrations in micrograms per milliliter. ${ }^{* \star} P<0.01$ for IL-12/IL-18 vs. IL-12/IL-18 + gp96-II peptide at $24 \mathrm{~h}$; ${ }^{\#} P<0.05$ and ${ }^{\# \# P}<0.001$ for IL-12/IL-18 vs. IL-12/IL-18 + gp96-II peptide at 48 h. Absence of a symbol indicates a non-significant difference.

study was therefore to investigate the inhibitory effect of gp96II on IFN $\gamma$, as it has previously been shown that gp96 protein expression is dose- and time dependently increased in vitro by IFN $\gamma$ in lymphoid and epithelial cancer cells $(7,35)$. We show that inhibition of gp96 with gp96-II peptide significantly inhibits IL-12/IL-18-induced INF $\gamma$ induction in vitro in PBMC as well as in murine splenocytes. To confirm the pivotal inhibitory effect of gp96-II peptide on IL-12/IL-18-induced inflammation in vivo, we utilized a chronic intestinal inflammation model in which a daily i.p. co-administration of IL-18 and IL-12 induces a severe systemic toxicity and type 1 immune response in mice, causing weight loss and increased serum cytokine levels $(15,19,20)$. Strikingly, animals treated with daily i.p. gp96-II peptide injections were exempt from all severe symptoms induced by daily IL-12/IL-18 injections and also suffered significantly less from systemic inflammation than control mice.

We investigated the longevity of the protective effects of gp96II peptide via ex vivo whole blood experiments. Our data presented here show that cells obtained from mice injected daily with IL-12/IL-18 and treated in vivo with gp96-II peptide exhibited 


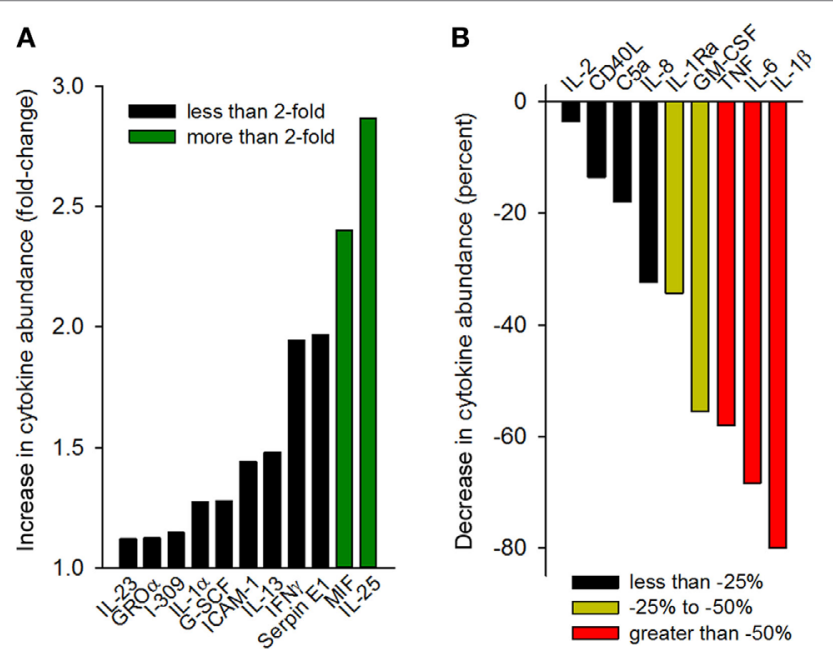

FIGURE 6 | Cytokine array analysis of supernatants of peripheral blood mononuclear cell cultures (two donors) treated with $100 \mathrm{ng} / \mathrm{ml}$ lipopolysaccharide with or without gp96-II peptide $(30 \mu \mathrm{g} / \mathrm{ml})$ for $24 \mathrm{~h}$. Densitometric analysis of the blots is depicted as normalized density per square millimeter. Panel (A) describes the increase in cytokine abundance (fold change) and panel (B) describes the decrease in cytokine abundance in percent.

a reduced pro-inflammatory cytokine expression when exposed to a "second hit" involving stimulation with a TLR2- or TLR4agonist or IL-1 $\beta$ when compared to vehicle-treated animals. Collectively, these findings suggest that gp96 has a prominent role in cytokine regulation of intestinal inflammation and that gp96-II peptide strongly and lastingly inhibits key cytokines such as IL- $1 \beta$, IFN $\gamma$, TNF and IL- 6 , thereby improving the outcome of murine intestinal inflammation (36).

To complement these investigations, we chose TNBS as our second model of murine intestinal inflammation, as the inflammation induced by TNBS is T cell driven and associated with elevated IFN $\gamma$, which causes epithelial injury of the colon. This model has been widely used to study cytokine secretion patterns and the effect of immunotherapies $(17,21)$. Elevated IFN $\gamma$ production is an invariable feature of IBD pathogenesis, as reviewed in detail in Ref. (37). In this context, it is relevant that TNBS colitis can be treated with antibodies to IL-12, one of the key inducers of IFN $\gamma$ (17). We therefore considered that TNBS-induced colitis is a model that is well-suited for testing the impact of continuous treatment with gp96-II peptide. Our study shows that TNBSchallenged mice, if treated with gp96-II, benefit from reduced weight loss, improved endoscopic scores and present with fewer morphological changes in the colon. Indeed, our data show that the inhibitor gp96-II peptide has anti-inflammatory properties as strong as those of prednisolone, which we used as a positive control in this setting. Clinically, corticosteroids are one of the mainstay therapies for IBD in human patients.

We can speculate that gp96-II peptide exerts its mechanistic effects by reducing the pro-inflammatory cytokines IL-1 $\beta$, IL-6, TNF, and IFN $\gamma$ in murine samples and in PBMC induced by different triggers. Interestingly the type 2-polarizing cytokine IL-25 was increased in PBMC, whereas IL-23, G-CSF, ICAM-1, IL-13,
IL-2, CD40L, C5a and IL-8 showed little or no change. Thus, gp96-II may act via induction of IL-25, which is well known to have protective effects in IBD (25). In this context, we note that IL-25 inhibits IL- 12 and Th- 1 cell-driven inflammation in colonic samples from patients and experimental colitis (38).

Several attempts have been made to introduce cytokinebased therapies for patients with IBD. However, to date, antiinflammatory cytokines such as IFN $\beta$ (34), IL-10 (39-41) and IL-11 (42) have failed to show benefit in patients with CD. A trial with a neutralizing antibody against IFN $\gamma$ (fontolizumab) was stopped despite showing some beneficial effect (43), while anti-IL-17A (secukinumab) aggravated CD (44). Initial results with the anti-TNF antibody infliximab in patients with CD $(45,46)$ and other anti-TNF therapies such as adalimumab and certolizumab, pointed to improved outcome of many patients with IBD (CD and UC), but within 1 year only a third maintained remission (47).

Our study was motivated by the clear need for novel targets and therapies for human intestinal inflammatory disease. That gp96 has multiple and potent pro-inflammatory effects is already well documented, including dendritic cell activation, type 1 immune polarization and downregulation of its own receptors in a negative feedback loop (5). These actions, in combination with the therapeutic benefits we report on its synthetic inhibitor gp96II peptide, makes gp96 a promising target for the development of therapies to restore intestinal homeostasis in IBD.

\section{ETHICS STATEMENT}

This study and protocol were carried out in accordance with the recommendations and approval by the Colorado Multiple Institutional Human Review Board. All subjects gave written informed consent in accordance with the Declaration of Helsinki. The animal studies and protocols were carried out in accordance with the recommendations of the Animal Review Board of the University of Colorado Denver and The University of Mainz Animal Care and Use Committee.

\section{AUTHOR CONTRIBUTIONS}

All authors were involved in drafting the article or revising it critically for important intellectual content, and all authors approved the final version to be published. CAD and CAN-P had full access to all of the data in the study and take responsibility for the integrity of the data and the accuracy of the data analysis. Study conception and design: CAD, CAN-P, CB, SW, and MN. Acquisition of data: CAN-P, MFN, OL, YK, AO, IB, CB, SW, and $\mathrm{MN}$. Analysis and interpretation of data: CAN-P, MFN, OL, YK, $\mathrm{AO}, \mathrm{IB}, \mathrm{MKS}, \mathrm{CB}, \mathrm{SW}$ and $\mathrm{MN}$.

\section{ACKNOWLEDGMENTS}

This study was supported by research grants from the Interleukin Foundation (to MFN and CAN-P), The Blair Ritchie Fellowship (CAN-P), R\&D Systems, a Fellowship by the Deutsche Forschungsgemeinschaft (to MFN), the Larkins Fellowship from Monash University (to MFN), the Victorian Government's 
Operational Infrastructure Support Program and a Future Leader Fellowship to CAN-P from the National Heart Foundation of Australia CF14/3517.

\section{SUPPLEMENTARY MATERIAL}

The Supplementary Material for this article can be found online at http://www.frontiersin.org/article/10.3389/fimmu.2017.01531/ full\#supplementary-material.

\section{REFERENCES}

1. Marsal J, Agace WW. Targeting T-cell migration in inflammatory bowel disease. J Intern Med (2012) 272(5):411-29. doi:10.1111/j.1365-2796.2012.02588.x

2. Multhoff G. Heat shock proteins in immunity. Handb Exp Pharmacol (2006) 172:279-304. doi:10.1007/3-540-29717-0_12

3. Yang Y, Liu B, Dai J, Srivastava PK, Zammit DJ, Lefrancois L, et al. Heat shock protein gp96 is a master chaperone for toll-like receptors and is important in the innate function of macrophages. Immunity (2007) 26(2):215-26. doi:10.1016/j.immuni.2006.12.005

4. Staron M, Yang Y, Liu B, Li J, Shen Y, Zuniga-Pflucker JC, et al. gp96, an endoplasmic reticulum master chaperone for integrins and toll-like receptors, selectively regulates early T and B lymphopoiesis. Blood (2010) 115(12): 2380-90. doi:10.1182/blood-2009-07-233031

5. Singh-Jasuja H, Scherer HU, Hilf N, Arnold-Schild D, Rammensee HG, Toes RE, et al. The heat shock protein gp96 induces maturation of dendritic cells and down-regulation of its receptor. Eur J Immunol (2000) 30(8):2211-5. doi:10.1002/1521-4141(2000)30:8<2211::AID-IMMU2211>3.0.CO;2-0

6. Singh-Jasuja H, Toes RE, Spee P, Munz C, Hilf N, Schoenberger SP, et al. Cross-presentation of glycoprotein 96-associated antigens on major histocompatibility complex class I molecules requires receptor-mediated endocytosis. J Exp Med (2000) 191(11):1965-74. doi:10.1084/jem.191.11.1965

7. Anderson SL, Shen T, Lou J, Xing L, Blachere NE, Srivastava PK, et al. The endoplasmic reticular heat shock protein gp96 is transcriptionally upregulated in interferon-treated cells. J Exp Med (1994) 180(4):1565-9. doi:10.1084/ jem.180.4.1565

8. Vabulas RM, Braedel S, Hilf N, Singh-Jasuja H, Herter S, Ahmad-Nejad P, et al. The endoplasmic reticulum-resident heat shock protein Gp96 activates dendritic cells via the toll-like receptor 2/4 pathway. JBiol Chem (2002) 277(23):20847-53. doi:10.1074/jbc.M200425200

9. Ito R, Shin-Ya M, Kishida T, Urano A, Takada R, Sakagami J, et al. Interferon-gamma is causatively involved in experimental inflammatory bowel disease in mice. Clin Exp Immunol (2006) 146(2):330-8. doi:10.1111/j.1365-2249.2006.03214.x

10. Pizarro TT, Michie MH, Bentz M, Woraratanadharm J, Smith MF Jr, Foley E, et al. IL-18, a novel immunoregulatory cytokine, is up-regulated in Crohn's disease: expression and localization in intestinal mucosal cells. J Immunol (1999) 162(11):6829-35

11. Monteleone G, Trapasso F, Parrello T, Biancone L, Stella A, Iuliano R, et al. Bioactive IL-18 expression is up-regulated in Crohn's disease. J Immunol (1999) 163(1):143-7.

12. Kanai T, Watanabe M, Okazawa A, Nakamaru K, Okamoto M, Naganuma M, et al. Interleukin 18 is a potent proliferative factor for intestinal mucosal lymphocytes in Crohn's disease. Gastroenterology (2000) 119(6):1514-23. doi:10.1053/gast.2000.20260

13. Monteleone G, Biancone L, Marasco R, Morrone G, Marasco O, Luzza F, et al. Interleukin 12 is expressed and actively released by Crohn's disease intestinal lamina propria mononuclear cells. Gastroenterology (1997) 112(4):1169-78. doi:10.1016/S0016-5085(97)70128-8

14. Parronchi P, Romagnani P, Annunziato F, Sampognaro S, Becchio A, Giannarini L, et al. Type 1 T-helper cell predominance and interleukin-12 expression in the gut of patients with Crohn's disease. Am J Pathol (1997) 150(3):823-32.

15. Chikano S, Sawada K, Shimoyama T, Kashiwamura SI, Sugihara A, Sekikawa K, et al. IL-18 and IL-12 induce intestinal inflammation and fatty
FIGURE S1 | Anti-inflammatory activity of nine gp96-|| peptides. gp96-|| peptide (30 $\mathrm{\mu M}$, open symbols) inhibits the production of cytokines from human peripheral blood mononuclear cells in response to a 24-h treatment with $1 \mu \mathrm{g} / \mathrm{ml}$ lipopolysaccharide (LPS) (A,B) or $48 \mathrm{~h}$ with $30 \mu \mathrm{g} / \mathrm{ml}$ anti-CD3 (C,D) in comparison to peptides gp96-I and III-X (30 $\mu \mathrm{M}$, solid symbols) and dexamethasone. Individual cytokine abundance is depicted with each symbol representing one biological replicate. Horizontal lines show means.

TABLE S1 | Stool consistency: normal stool, stool with an appearance of wellformed pellets; slightly loose stool, loose stool with pasty, semi-formed, soft materials that do not adhere to anal fur; diarrhea, liquid stool that adheres to anal fur. Gross bleeding, an appearance of visible blood adhering to anal fur.

liver in mice in an IFN-gamma dependent manner. Gut (2000) 47(6):779-86. doi:10.1136/gut.47.6.779

16. Ishikura T, Kanai T, Uraushihara K, Iiyama R, Makita S, Totsuka T, et al. Interleukin-18 overproduction exacerbates the development of colitis with markedly infiltrated macrophages in interleukin-18 transgenic mice. J Gastroenterol Hepatol (2003) 18(8):960-9. doi:10.1046/j.1440-1746.2003.03097.x

17. Neurath MF, Fuss I, Kelsall BL, Stuber E, Strober W. Antibodies to interleukin 12 abrogate established experimental colitis in mice. J Exp Med (1995) 182(5):1281-90. doi:10.1084/jem.182.5.1281

18. Okamura H, Tsutsi H, Komatsu T, Yutsudo M, Hakura A, Tanimoto T, et al. Cloning of a new cytokine that induces IFN-gamma production by $\mathrm{T}$ cells. Nature (1995) 378(6552):88-91. doi:10.1038/378088a0

19. Okamura H, Kashiwamura S, Tsutsui H, Yoshimoto T, Nakanishi K. Regulation of interferon-gamma production by IL-12 and IL-18. Curr Opin Immunol (1998) 10(3):259-64. doi:10.1016/S0952-7915(98)80163-5

20. Carson WE, Dierksheide JE, Jabbour S, Anghelina M, Bouchard P, Ku G, et al. Coadministration of interleukin-18 and interleukin-12 induces a fatal inflammatory response in mice: critical role of natural killer cell interferon-gamma production and STAT-mediated signal transduction. Blood (2000) 96(4):1465-73.

21. Wirtz S, Popp V, Kindermann M, Gerlach K, Weigmann B, FichtnerFeigl S, et al. Chemically induced mouse models of acute and chronic intestinal inflammation. Nat Protoc (2017) 12(7):1295-309. doi:10.1038/nprot.2017.044

22. Kliger Y, Levy O, Oren A, Ashkenazy H, Tiran Z, Novik A, et al. Peptides modulating conformational changes in secreted chaperones: from in silico design to preclinical proof of concept. Proc Natl Acad Sci U S A (2009) 106(33):13797-801. doi:10.1073/pnas.0906514106

23. Wu S, Dole K, Hong F, Noman AS, Issacs J, Liu B, et al. Chaperone gp96independent inhibition of endotoxin response by chaperone-based peptide inhibitors. J Biol Chem (2012) 287(24):19896-903. doi:10.1074/jbc. M112.343848

24. Ochayon DE, Mizrahi M, Shahaf G, Baranovski BM, Lewis EC. Human alpha1-antitrypsin binds to heat-shock protein gp 96 and protects from endogenous gp96-mediated injury in vivo. Front Immunol (2013) 4:320. doi:10.3389/ fimmu.2013.00320

25. McHenga SS, Wang D, Li C, Shan F, Lu C. Inhibitory effect of recombinant IL-25 on the development of dextran sulfate sodium-induced experimental colitis in mice. Cell Mol Immunol (2008) 5(6):425-31. doi:10.1038/cmi.2008.53

26. Nold MF, Nold-Petry CA, Zepp JA, Palmer BE, Bufler P, Dinarello CA. IL-37 is a fundamental inhibitor of innate immunity. Nat Immunol (2010) 11(11):1014-22. doi:10.1038/ni.1944

27. Becker C, Fantini MC, Wirtz S, Nikolaev A, Kiesslich R, Lehr HA, et al. In vivo imaging of colitis and colon cancer development in mice using high resolution chromoendoscopy. Gut (2005) 54(7):950-4. doi:10.1136/gut.2004.061283

28. Kanai T, Watanabe M, Okazawa A, Sato T, Yamazaki M, Okamoto S, et al. Macrophage-derived IL-18-mediated intestinal inflammation in the murine model of Crohn's disease. Gastroenterology (2001) 121(4):875-88. doi:10.1053/ gast.2001.28021

29. Siegmund B, Fantuzzi G, Rieder F, Gamboni-Robertson F, Lehr HA, Hartmann G, et al. Neutralization of interleukin-18 reduces severity in murine colitis and intestinal IFN-gamma and TNF-alpha production. Am J Physiol Regul Integr Comp Physiol (2001) 281(4):R1264-73.

30. Wirtz S, Becker C, Blumberg R, Galle PR, Neurath MF. Treatment of T celldependent experimental colitis in SCID mice by local administration of an adenovirus expressing IL-18 antisense mRNA. J Immunol (2002) 168(1): 411-20. doi:10.4049/jimmunol.168.1.411 
31. Rolhion N, Barnich N, Bringer MA, Glasser AL, Ranc J, Hebuterne X, et al. Abnormally expressed ER stress response chaperone Gp96 in CD favours adherent-invasive Escherichia coli invasion. Gut (2010) 59(10):1355-62. doi:10.1136/gut.2010.207456

32. Ng SC, Benjamin JL, McCarthy NE, Hedin CR, Koutsoumpas A, Plamondon S, et al. Relationship between human intestinal dendritic cells, gut microbiota, and disease activity in Crohn's disease. Inflamm Bowel Dis (2011) 17(10):2027-37. doi:10.1002/ibd.21590

33. Fantuzzi G, Puren AJ, Harding MW, Livingston DJ, Dinarello CA. Interleukin-18 regulation of interferon gamma production and cell proliferation as shown in interleukin-1beta-converting enzyme (caspase-1)-deficient mice. Blood (1998) 91(6):2118-25.

34. Pena Rossi C, Hanauer SB, Tomasevic R, Hunter JO, Shafran I, Graffner H. Interferon beta-1a for the maintenance of remission in patients with Crohn's disease: results of a phase II dose-finding study. BMC Gastroenterol (2009) 9:22. doi:10.1186/1471-230X-9-22

35. Chen YG, Ashok BT, Liu X, Garikapaty VP, Mittelman A, Tiwari RK. Induction of heat shock protein gp96 by immune cytokines. Cell Stress Chaperones (2003) 8(3):242-8. doi:10.1379/1466-1268(2003)008<0242:IOHSPG>2.0.CO;2

36. Neurath MF. Cytokines in inflammatory bowel disease. Nat Rev Immunol (2014) 14(5):329-42. doi:10.1038/nri3661

37. Strober W, Fuss IJ. Proinflammatory cytokines in the pathogenesis of inflammatory bowel diseases. Gastroenterology (2011) 140(6):1756-67. doi:10.1053/j.gastro.2011.02.016

38. Caruso R, Sarra M, Stolfi C, Rizzo A, Fina D, Fantini MC, et al. Interleukin-25 inhibits interleukin-12 production and Th1 cell-driven inflammation in the gut. Gastroenterology (2009) 136(7):2270-9. doi:10.1053/j.gastro.2009.02.049

39. Colombel JF, Rutgeerts P, Malchow H, Jacyna M, Nielsen OH, Rask-Madsen J, et al. Interleukin 10 (Tenovil) in the prevention of postoperative recurrence of Crohn's disease. Gut (2001) 49(1):42-6. doi:10.1136/gut.49.1.42

40. Schreiber S, Fedorak RN, Nielsen OH, Wild G, Williams CN, Nikolaus S, et al. Safety and efficacy of recombinant human interleukin 10 in chronic active Crohn's disease. Crohn's Disease IL-10 Cooperative Study Group. Gastroenterology (2000) 119(6):1461-72. doi:10.1053/gast.2000.20196

41. Fedorak RN, Gangl A, Elson CO, Rutgeerts P, Schreiber S, Wild G, et al. Recombinant human interleukin 10 in the treatment of patients with mild to moderately active Crohn's disease. The Interleukin 10 Inflammatory Bowel Disease Cooperative Study Group. Gastroenterology (2000) 119(6):1473-82. doi:10.1053/gast.2000.20229
42. Herrlinger KR, Witthoeft T, Raedler A, Bokemeyer B, Krummenerl T, Schulzke JD, et al. Randomized, double blind controlled trial of subcutaneous recombinant human interleukin-11 versus prednisolone in active Crohn's disease. Am J Gastroenterol (2006) 101(4):793-7. doi:10.1111/j. 1572-0241.2005.00356.x

43. Reinisch W, Hommes DW, Van Assche G, Colombel JF, Gendre JP, Oldenburg B, et al. A dose escalating, placebo controlled, double blind, single dose and multidose, safety and tolerability study of fontolizumab, a humanised anti-interferon gamma antibody, in patients with moderate to severe Crohn's disease. Gut (2006) 55(8):1138-44. doi:10.1136/gut.2005. 079434

44. Hueber W, Sands BE, Lewitzky S, Vandemeulebroecke M, Reinisch W, Higgins PD, et al. Secukinumab, a human anti-IL-17A monoclonal antibody, for moderate to severe Crohn's disease: unexpected results of a randomised, double-blind placebo-controlled trial. Gut (2012) 61(12):1693-700. doi:10.1136/gutjnl-2011-301668

45. Derkx B, Taminiau J, Radema S, Stronkhorst A, Wortel C, Tytgat G, et al. Tumour-necrosis-factor antibody treatment in Crohn's disease. Lancet (1993) 342(8864):173-4. doi:10.1016/0140-6736(93)91375-V

46. van Dullemen HM, van Deventer SJ, Hommes DW, Bijl HA, Jansen J, Tytgat GN, et al. Treatment of Crohn's disease with anti-tumor necrosis factor chimeric monoclonal antibody (cA2). Gastroenterology (1995) 109(1):129-35. doi:10.1016/0016-5085(95)90277-5

47. Peyrin-Biroulet L, Lemann M. Review article: remission rates achievable by current therapies for inflammatory bowel disease. Aliment Pharmacol Ther (2011) 33(8):870-9. doi:10.1111/j.1365-2036.2011.04599.x

Conflict of Interest Statement: The authors declare that the research was conducted in the absence of any commercial of financial interest that could be considered as a potential conflict of interest. Gp96-II was an in kind contribution from Compugen Ltd., 26 Harokmim Street, Holon 5885800, Israel.

Copyright (c) 2017 Nold-Petry, Nold, Levy, Kliger, Oren, Borukhov, Becker, Wirtz, Sandhu, Neurath and Dinarello. This is an open-access article distributed under the terms of the Creative Commons Attribution License (CC BY). The use, distribution or reproduction in other forums is permitted, provided the original author(s) or licensor are credited and that the original publication in this journal is cited, in accordance with accepted academic practice. No use, distribution or reproduction is permitted which does not comply with these terms. 